\title{
QUEEN'S
QNEIVERSITY
BELFAST
}

\section{Wholly Biobased, Highly Stretchable, Hydrophobic, and Self-healing Thermoplastic Elastomer}

Nurhamiyah, Y., Amir, A., Finnegan, M., Themistou, E., Edirisinghe, M., \& Chen, B. (2021). Wholly Biobased, Highly Stretchable, Hydrophobic, and Self-healing Thermoplastic Elastomer. ACS Applied Materials and Interfaces, 13(5), 6720-6730. https://doi.org/10.1021/acsami.0c23155

Published in:

ACS Applied Materials and Interfaces

Document Version:

Peer reviewed version

Queen's University Belfast - Research Portal:

Link to publication record in Queen's University Belfast Research Portal

Publisher rights

Copyright 2021 ACS. This work is made available online in accordance with the publisher's policies. Please refer to any applicable terms of use of the publisher.

\section{General rights}

Copyright for the publications made accessible via the Queen's University Belfast Research Portal is retained by the author(s) and / or other copyright owners and it is a condition of accessing these publications that users recognise and abide by the legal requirements associated with these rights.

Take down policy

The Research Portal is Queen's institutional repository that provides access to Queen's research output. Every effort has been made to ensure that content in the Research Portal does not infringe any person's rights, or applicable UK laws. If you discover content in the Research Portal that you believe breaches copyright or violates any law, please contact openaccess@qub.ac.uk. 


\title{
Wholly Biobased, Highly Stretchable,
}

\section{Hydrophobic and Self-healing Thermoplastic}

\section{Elastomer}

Yeyen Nurhamiyah ${ }^{1}$, Amalina Amir ${ }^{2}$, Marie Finnegan ${ }^{3}$, Efrosyni Themistou ${ }^{3}$, Mohan Edirisinghe ${ }^{2}$, and Biqiong Chen ${ }^{1}$,

${ }^{1}$ School of Mechanical and Aerospace Engineering, Queen's University Belfast, Stranmillis Road, Belfast BT9 5AH, United Kingdom

${ }^{2}$ Department of Mechanical Engineering, University College London, Torrington Place, London WC1E 7JE, United Kingdom

${ }^{3}$ School of Chemistry and Chemical Engineering, Queen's University Belfast, Stranmillis Road, Belfast BT9 5AG, United Kingdom

\begin{abstract}
Renewable polymers with excellent stretchability and self-healing ability are interesting for a wide range of applications. A novel type of wholly biobased, self-healing, polyamide-based thermoplastic elastomer was synthesized using a fatty dimer acid and a fatty dimer amine, both containing multiple alkyl chains, through facile one-pot condensation polymerization under different polymerization times. The resulting elastomer shows superior stretchabiblity (up to 2286\%), high toughness, and excellent shape recovery after being stretched to different strains. This elastomer also displays high room temperature autonomous self-healing efficiency after fracture and zero water uptake during water immersion. The highly entangled main chain, the multiple dangling chains, the abundant reversible physical bonds, the inter-molecular diffusion and the low ratio of amide to methylene
\end{abstract}


group within the elastomer are responsible for these extraordinary properties. The polymerization time influences the properties of the elastomer. The use of the optimal self-healing thermoplastic elastomer in anti-corrosion coating, piezoresistive sensing and highly stretchable fibres is also demonstrated. The elastomer coating prevents stainless-steel products from corrosion in a salty environment due to its superhydrophobicity. The elastomer serves as a robust flexible substrate for creating self-healing piezoresistive sensors with excellent repeatability and self-healing efficiency. The elastomer fibre yarn can be stretched to $950 \%$ of its original length confirming its outstanding stretchability.

Keywords: self-healing elastomers, biobased polyamides, hydrophobicity, anti-corrosion coatings, sensors, fibres

\section{Introduction}

Elastomers are an important class of materials, which are widely found in different sectors of business, such as car tires, sealings, tubings, texitles, medical devices, electronic devices and daily commodities. ${ }^{1,2}$ Due to irreversible covalent bonds, conventional elastomers are generally not selfhealing. Currently, new types of elastomers are being developed with attractive features including high stretchability and self-healability. The outstanding characteristics of self-healing elastomers open up opportunities for their use in high-end applications, such as smart flexible electronics, electronic skin, werarable devices, and soft robots. ${ }^{3-7}$ Autonomous self-healing elastomers are desirable since they can self-heal after experiencing damage without any external intervention. Selfhealing ability in elastomers is enabled through dynamic covalent bonds such as Diels Alder reaction, ${ }^{8,9}$ disulfide bond, ${ }^{10,11}$ and boronic ester/oxide, ${ }^{12,13}$ physical bonds such as hydrogen bond ,${ }^{14,15}$ metal-ligand interaction, ${ }^{16,17}$ ionic interaction, ${ }^{18}$ host-guest interaction, ${ }^{19}$ and van der Waals force, ${ }^{20}$ or a combination of different bonds. ${ }^{21}$ An autonomous self-healing elastomer created by supramolecular assembly via multiple hydrogen bonds was synthesized from a mixture of di- and tri- 
fatty acids, along with diethylenetriamine and urea. ${ }^{22}$ A self-healing thermoplastic polyurethane formed via dynamic covalent disulfide bonds was produced for scratch-detecting electrical sensors. ${ }^{23}$ A self-healing dielectric elastomer was obtained from the functionalization of a nonpolar polydimethylsiloxane polymer with metal-ligand interactions. ${ }^{24} \mathrm{~A}$ series of poly(methyl methacrylate-co- $n$-butyl acrylate) copolymers and their derivatives were synthesized and displayed self-healing behavior through van der Waals forces. ${ }^{20}$

However, none of the autonomous self-healing elastomers reported to date is wholly biobased; a few existing biobased examples ${ }^{22,25}$ are partially biobased or not $100 \%$ renewable. Most of the selfhealing elastomer synthesis involved several steps with the use of toxic chemicals, which are costineffective, energy-inefficient, difficult for scale-up production and undesirable for green plastic production. Further, some self-healing elastomers cannot melt and are water-sensitive due to their branched structures and abundant polar groups, making the manufacturing process inflexible and limiting their wider application. Melt processing is the most common method used in polymer processing industry which is environmentally friendly. The diverse elastomer research towards sustainable, environmentally friendly and energy-efficient production is becoming growingly attractive due to the serious concerns associated with the depletion of fossil-based resources and production of greenhouse gas emissions.

In this work, we report a new type of wholly biobased, room temperature autonomous self-healing elastomer with superior stretchability, high self-healing efficiency, zero water uptake and meltprocessability, which can be synthesized by one-pot condensation polymerization without using any additives. A fatty diamine (CRODA $®$ Priamine 1075) and a fatty dicarboxylic acid (CRODA® Pripol 1009), each containing four alkyl chains with 36 carbon atoms in total, were selected as the monomers for the synthesis of the new polyamide-based thermoplastic elastomer (PA36,36) (Figure 1a) to ensure its renewability and desirable performances. Due to the long entangled alkyl main chain and the multiple alkyl dangling chains, it is hypothesized that strong physical and reversible crosslinks can form through the abundant van der Waals bonds between the alkyl chains (Figure 1b), creating 
a highly stretchable and autonomously self-healing elastomer. The two monomers with the stoichiometrically equivalent ratio were polymerized in a nitrogen atmosphere at $220{ }^{\circ} \mathrm{C}$ under different periods of time ( $8 \mathrm{~h}, 16 \mathrm{~h}, 24 \mathrm{~h}, 32 \mathrm{~h})$ to determine the optimal polymerization time, and the resulting polymers are denoted as PA36,36(xh), where $\mathrm{x}$ represents the number of polymerization hours. The use of the optimal self-healing elastomer in anti-corrosion coating, piezoresistive sensing and highly stretchable fibres is also investigated to explore its potential applications.

\section{Results and Discussion}
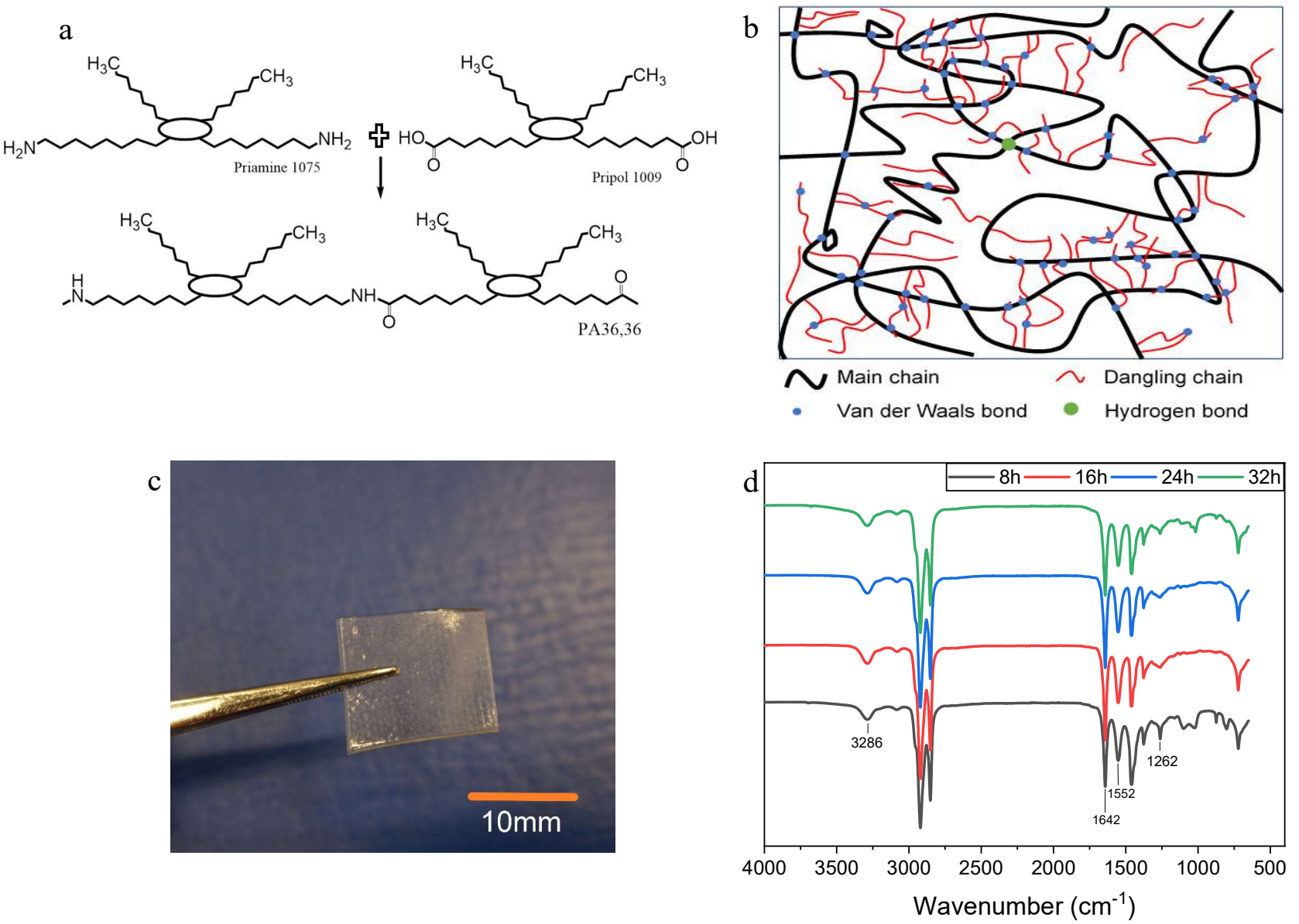

Figure 1. (a) Polymerization reaction scheme of PA36,36 from Priamine 1075 and Pripol 1009. (b)

Illustration of the supramolecular structure of PA36,36 due to the presence of the long entangled main chains, multiple dangling chains, abundament van der Waals bonds and minor hydrogen bonds, attributable to its high stretchability and self-healing efficiency. (c) Macro-photograph of a PA36,36. (d) FTIR spectra of PA36,36s prepared with different polymerization times. 
All the four polyamides (PA36,36s) synthesized display softness, high stretchability, and yellowish transparent appearance (Figure 1c). Their chemical structures are confirmed by Fourier transform infared spectroscopy (FTIR) (Figure 1d), showing successful synthesis of polyamides. The presence of amide bonds is detected at several wavenumbers: at $3286 \mathrm{~cm}^{-1}$ attributable to N-H stretching in amide $\mathrm{A}$; at $1642 \mathrm{~cm}^{-1}$ for $\mathrm{C}=\mathrm{O}$ stretching in amide $\mathrm{I}$; at $1552 \mathrm{~cm}^{-1}$ for $\mathrm{N}-\mathrm{H}$ in-plane bending coupled with $\mathrm{C}-\mathrm{N}$ and $\mathrm{C}-\mathrm{O}$ stretching in amide II and at $1262 \mathrm{~cm}^{-1}$ for $\mathrm{N}-\mathrm{H}$ bending in amide $\mathrm{III} .{ }^{26}$ Aliphatic $\mathrm{CH}_{2}$ groups are confirmed with strong peaks at $2920 \mathrm{~cm}^{-1}, 2851 \mathrm{~cm}^{-1}, 1461 \mathrm{~cm}^{-1}$ and $1376 \mathrm{~cm}^{-1} .^{27}$ This is supported by the results from ${ }^{1} \mathrm{H}$ Nuclear Magnetic Resonance (NMR) and ${ }^{13} \mathrm{C}$ NMR (Figure S1, Supporting Information), which show the chemical shifts for the monomers, the polyamides and evidence of the four methylene dangling chains.

The PA36,36s show high weight average molecular weights $\left(\overline{\mathrm{M}}_{w}\right)$ in the range of $142,400-185,600$ g.mol ${ }^{-1}$ and relatively broad molecular weight distributions (polydispersity index (PDI): $3.51-4.62$ ) by gel permeation chromatography (GPC) in tetrahydrofuran (Figure 2a, Table S1). In addition, there are $3-5 \%$ oligomers within the polymers, shown as small peaks at Log M of 3.2 and 3.5, respectively. Polymerization time affects the molecular weight of PA36,36, with PA36,36(32h) having the highest molecular weight. After the synthetic process, the PA36,36s were hot pressed at $120^{\circ} \mathrm{C}$ to prepare mechanical testing specimens, which affects the molecular weight slightly (Figure S2, Table S1). The molecular weight of PA36,36(8h, 16h and 24h) slightly increased after hot pressing suggesting that hot pressing allows for further reaction which is dominant compared to thermal degradation. ${ }^{28}$ In contrast, a decrease in the number average molecular weight $\left(\overline{\mathrm{M}}_{\mathrm{n}}\right)$ was found in PA36,36(32h) after hot pressing, attributable to the dominant role of thermal degradation that suppressed the effect of any further reactions. ${ }^{28}$ Due to the presence of multiple dangling chains, the PA36,36s are amorphous, with no melting peak detected upon heating by differential scanning calorimetry. 

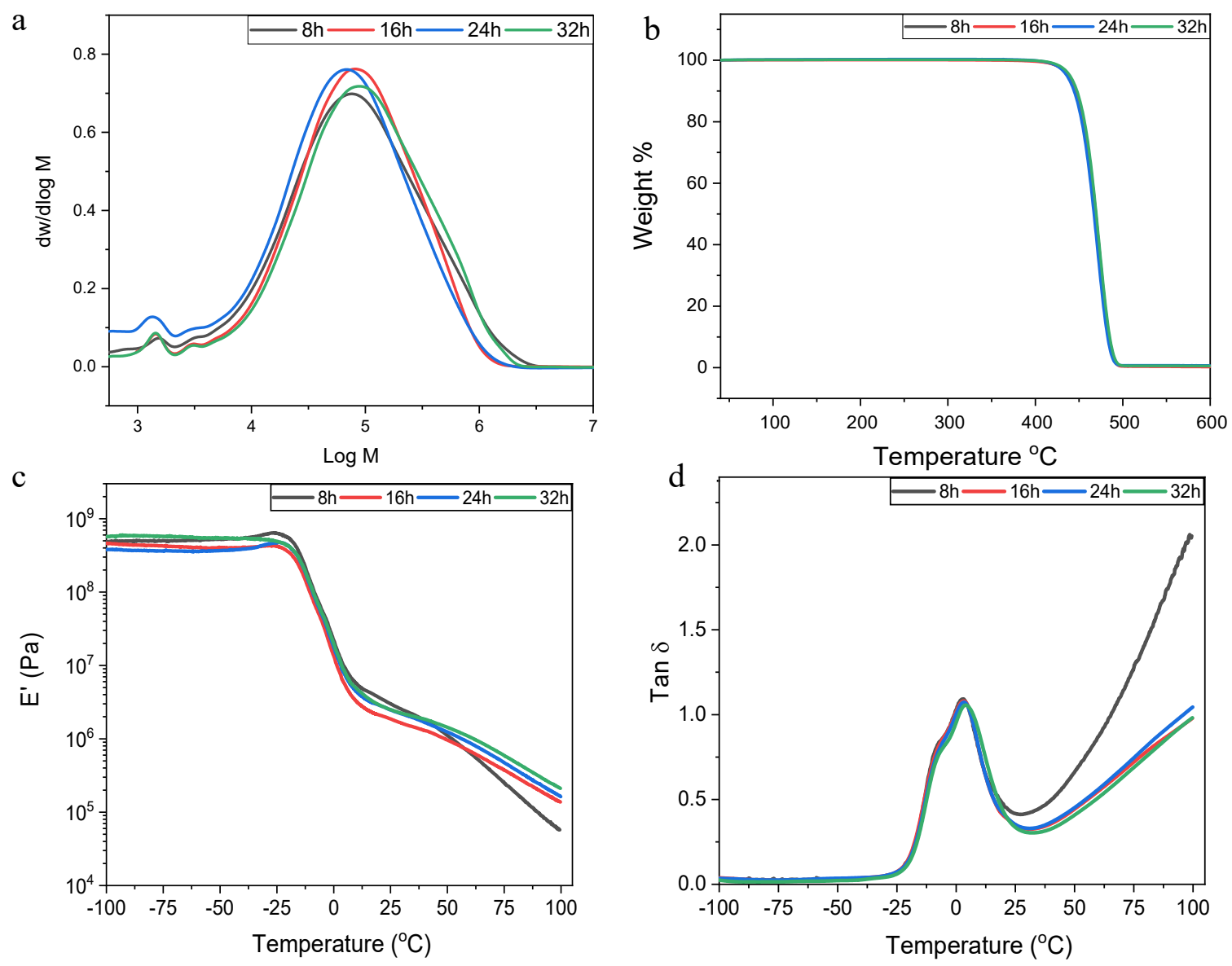

Figure 2. (a) GPC traces, (b) TGA traces, (c) storage modulus and (d) loss factor versus temperature from DMA for PA36,36 prepared with different polymerization times.

Thermogravimetric analysis (TGA) was conducted to study the thermal degradation behavior of PA36,36s (Figure 2b, Table S2). All four samples exhibit almost the same curves implying very similar thermal degradation behavior. The onset thermal degradation temperature of all the PA36,36s starts at $438^{\circ} \mathrm{C}$ after which decomposition becomes rapid until no significant residue. The differential thermogravimetric analysis (DTG) shows that the peak thermal degradation temperature $\left(\mathrm{T}_{\mathrm{d}}^{\text {peak }}\right)$ occurs at $471-473{ }^{\circ} \mathrm{C}$ (Figure S3). $\mathrm{T}_{\mathrm{d}}$ of PA36,36 is insignificantly affected by the polymerization time. Further, this degradation temperature is similar to those of conventional polyamides, such as PA11 that has a $\mathrm{T}_{\mathrm{d}}^{\text {peak }}$ of $470{ }^{\circ} \mathrm{C} .{ }^{29}$ The thermal decomposition of aliphatic polyamides begins either in the carbonyl methylene group or the methylene group adjacent to $\mathrm{NH} .{ }^{30}$ Inorganic gases such as $\mathrm{CO}_{2}, \mathrm{H}_{2} \mathrm{O}, \mathrm{NH}_{3}$ and $\mathrm{HCN}$ are the main products of thermal degradation in polyamides. ${ }^{31}$ The high 
thermal degradation temperatures of these PA36,36s demonstrate their excellent resistance to thermal degradation.

The dynamic mechanical analysis (DMA) shows a rubbery plateau for the PA36,36s within $10-50$ ${ }^{\circ} \mathrm{C}$ with storage modulus of $1-4 \mathrm{MPa}$ (Figure 2c), which indicates elastomeric behaviour. ${ }^{32}$ The PA36,36s display glass transition temperatures $\left(\mathrm{T}_{\mathrm{g}}\right)$, determined as the peak value of $\tan \delta$ (Figure 2d), in the range of $3.1-4.1{ }^{\circ} \mathrm{C}$ (Table S2). Higher polymerization time only results in a slightly higher $\mathrm{T}_{\mathrm{g}} \mathrm{T}_{\mathrm{g}}$ of a PA is related to the chain length of the monomers and the amount of amide groups in the chain, among others, so PA36,36s have a much lower $\mathrm{T}_{\mathrm{g}}$ than the values for conventional rigid PAs, i.e. PA6 $\left(78^{\circ} \mathrm{C}\right)$, PA6,6 $\left(80^{\circ} \mathrm{C}\right)$, and PA1 $1\left(68^{\circ} \mathrm{C}\right) .{ }^{33}$ The low $\mathrm{T}_{\mathrm{g}}$ ensures polymer mobility at ambient temperature, facilitating autonomous self-healing. ${ }^{17,34}$

The representative tensile stress-strain curves of PA36,36s are shown in Figure 3a, which have a similar shape to that of thermoplastic elastomers including polyamide-based thermoplastic elastomers. ${ }^{35,36}$ All PA36,36s display remarkable stretchability (Figure 3a,b). PA36,36(8h) can be stretched to $2286 \pm 135 \%$ under a strain rate of $100 \mathrm{~mm} \cdot \mathrm{min}^{-1}$, which is 22.9 times its original length (Table 1). While PA36,36s demonstrate reducing elongation at break with increasing polymerization time, PA36,36(24h) and PA36,36(32h) still show very high values of elongation at break, being 1932 \pm 147 and $1688 \pm 279$, respectively. The long and entangled alkyl chains with "hidden lengths" 37 presented within the dynamic physical crosslinks of PA36,36 (Figure 1b) ensures such high stretchability; during stretching the long alkyl chains disentangle followed by the breaking of physical bonds which release the hidden chains to be further stretched.

The wholly biobased PA36,36s possess the highest elongation at break within aliphatic polyamides (non-self-healing) and comparable (or even higher) stretchability with existing polyamide-based copolymer thermoplastic elastomers (non-self-healing). The elongation at break was $124 \%$ for PA6, 10, 121\% for PA10,12, ${ }^{38} 600 \%$ for a tall oil-based polyamide, ${ }^{39} \sim 600 \%$ for fatty dimer acid 


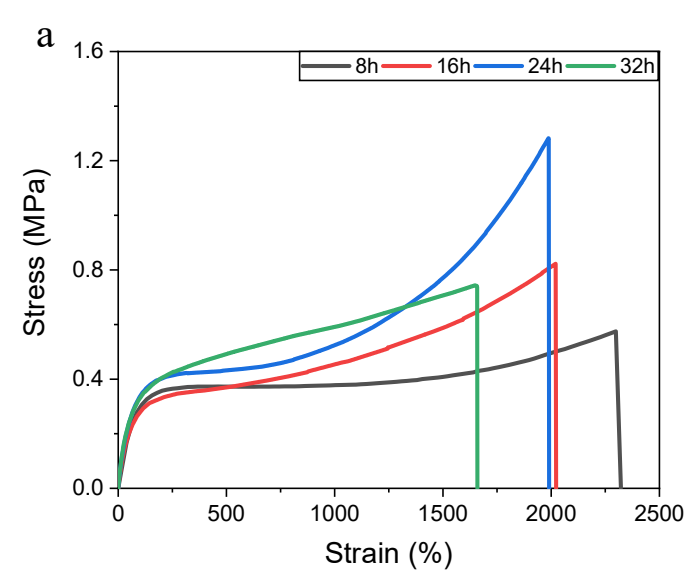

$\mathrm{b}$
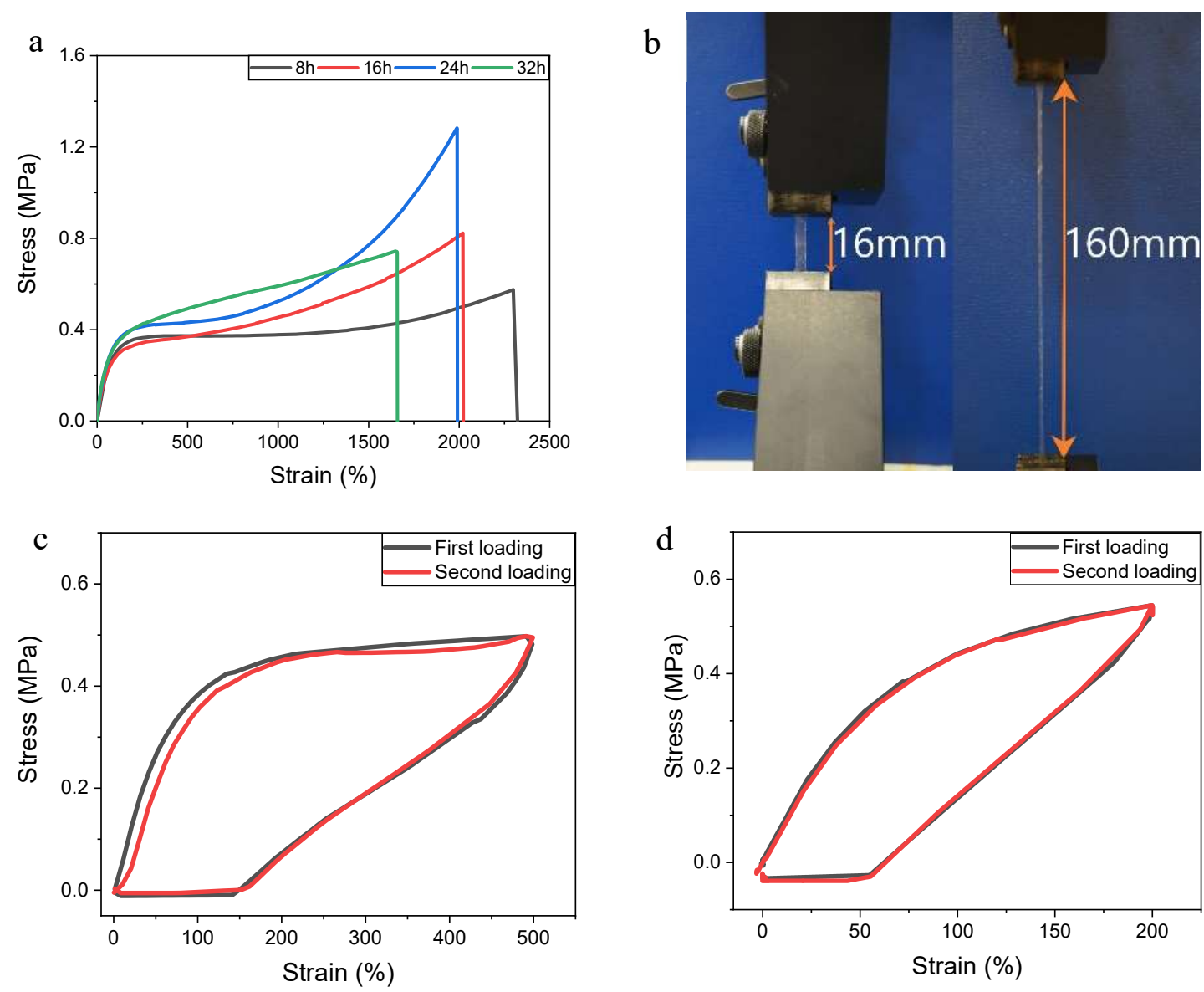

Figure 3. (a) Representative tensile stress-strain curves of PA36,36s prepared with different polymerization times. (b) A sample of PA36,36(24h) being stretched to 10 times its original length (the sample can be further stretched to nearly 20 times which became too thin to be legible in the image). (c) Loading-unloading cycles of PA36,36(24h) up to 500\% strain: first loading (black) and second loading (red) after 30 minutes' rest. (d) Loading-unloading cycles of PA36,36(24h) up to 200\% strain: first loading (black) and second loading (red) after 10 minutes' rest.

based polyamides,$^{40} 580-750 \%$ for poly $\left(N, N^{\top}\right.$-(2-hydroxypropane-1,3-diyl)bis(undec-10-namide)co-1,3-di(undec-10-enamido)propan-2yl butyrate, ${ }^{41}$ and $350-2200 \%$ for non-biobased poly(etherblock-amide) thermoplastic elastomers with different PA contents. ${ }^{42}$ The stretchability is also higher than those of other biobased self-healing elastomers such as $\sim 620 \%$ for a fatty acid based self-healing rubber, ${ }^{22}$ and $213 \%$ for histidine-grafted poly(oleic acid) coordinated with $\mathrm{Zn}$ ions, ${ }^{25}$ and comparable to the values for non-biobased self-healing elastomers such as $310-1570 \%$ for a hydrogen-bonded brush polymer, ${ }^{43} 1182 \%$ for $\mathrm{Cu}(\mathrm{II})$-dimethylglyoxime-urethane-complex based polyurethane 
elastomer, ${ }^{44} 923 \%$ for a thermoplastic polyurethane, ${ }^{23} 2200 \%$ for a poly(dimethylsiloxane) crosslinked with aromatic disulfide bond and imine bond, ${ }^{45}$ and $700 \%$ for a poly(dimethylsiloxane) crosslinked with $1,3,5$-triformylbenzene. ${ }^{46}$

The tensile strength and Young's modulus of PA36,36s also vary with polymerization time (Table 1); they reach their highest values at $24 \mathrm{~h}$, being $1.27 \pm 0.34 \mathrm{MPa}$ and $1.14 \pm 0.12 \mathrm{MPa}$, respectively. The highest tensile strength of PA36,36(24h) is attributable to its highest $\overline{\mathrm{M}}_{\mathrm{n}}\left(44,300 \mathrm{~g} \cdot \mathrm{mol}^{-1}\right)$ after hot pressing. ${ }^{47}$ Further, PA36,36(24h) shows the highest energy at break (toughness) of $14.21 \pm 4.58$ MJ.m ${ }^{-3}$, resulting from its highest strength, modulus and relatively high elongation at break. Since PA36,36(24h) exhibits the optimal combination of stretchability, strength, stiffness and toughness among the four samples investigated, it was chosen for subsequent studies.

Table 1. Tensile properties of PA36,36s

\begin{tabular}{|c|c|c|c|c|}
\hline Sample & $\begin{array}{c}\text { Tensile Strength } \\
(\mathrm{MPa})\end{array}$ & $\begin{array}{c}\text { Young's Modulus } \\
(\mathrm{MPa})\end{array}$ & $\begin{array}{c}\text { Elongation at } \\
\text { Break (\%) }\end{array}$ & $\begin{array}{c}\text { Tensile Energy at } \\
\text { Break }\left({\left.\mathrm{MJ} . \mathrm{m}^{-3}\right)}\right.\end{array}$ \\
\hline PA36,36(8h) & $0.61 \pm 0.08$ & $0.48 \pm 0.08$ & $2286 \pm 135$ & $9.30 \pm 0.89$ \\
\hline PA36,36(16h) & $0.81 \pm 0.10$ & $0.68 \pm 0.05$ & $2107 \pm 317$ & $10.24 \pm 1.84$ \\
\hline PA36,36(24h) & $1.27 \pm 0.34$ & $1.14 \pm 0.12$ & $1932 \pm 147$ & $14.21 \pm 4.58$ \\
\hline PA36,36(32h) & $0.81 \pm 0.06$ & $0.82 \pm 0.11$ & $1688 \pm 279$ & $9.77 \pm 1.48$ \\
\hline
\end{tabular}

Cyclic tensile loading-unloading testing results of PA36,36(24h) (Figure 3c,d) show the ability of PA36,36 to recover its original shape after a short period of resting time. The polymer was first stretched to $500 \%$, which was subsequently unloaded at the same strain rate of $100 \mathrm{~mm} . \mathrm{min}^{-1}$ and allowed to rest for $30 \mathrm{~min}$ before the second loading was applied. The second loading curve is almost identical to that of the first loading. When the polymer was streched to $200 \%$ it only needed $10 \mathrm{~min}$ to recover its original shape. PA36,36 demonstrates excellent ability of shape recovery. Compared to other self-healing elastomers that require $90 \mathrm{~min}$ to recover after streched to $300 \%$ at the same strain rate, ${ }^{48}$ or heat as external stimulus to recover its original state, ${ }^{49} \mathrm{PA} 36,36(24 \mathrm{~h})$ shows superior shape 
recovery. The excellent shape recovery is attributable to the ample van der Waals bonds between the main chains and/or the dangling chains that act as dynamic physical crosslinks in the elastomer (Figure 1b). The residual strains at zero stress observed in Figure 3c (150\%) and Figure 3d (60\%) during the unloading process imply that the polymer chains do not have sufficient time to recover their original shape fully under the high strain rate $\left(100 \mathrm{~mm} \cdot \mathrm{min}^{-1}\right)$. Residual strains are often found in thermoplastic elastomers which have been stretched to large strains $(200-1000 \%)$ and unloaded at high strain rates. ${ }^{48,50,51}$

a

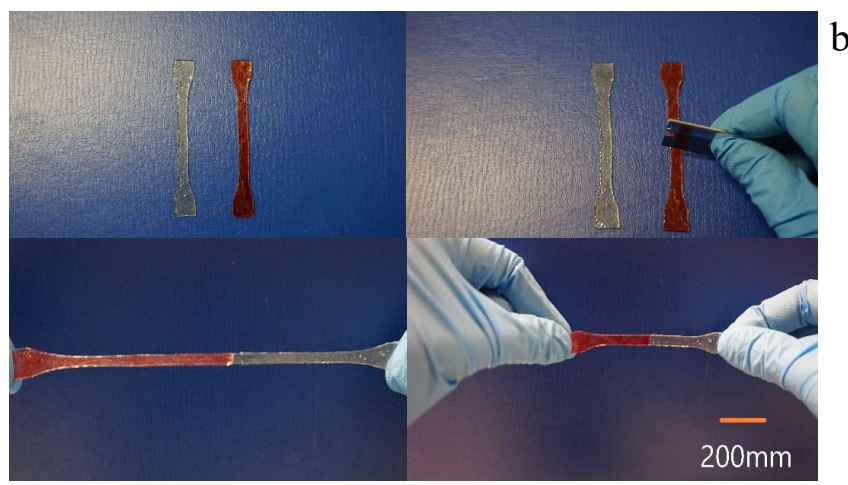

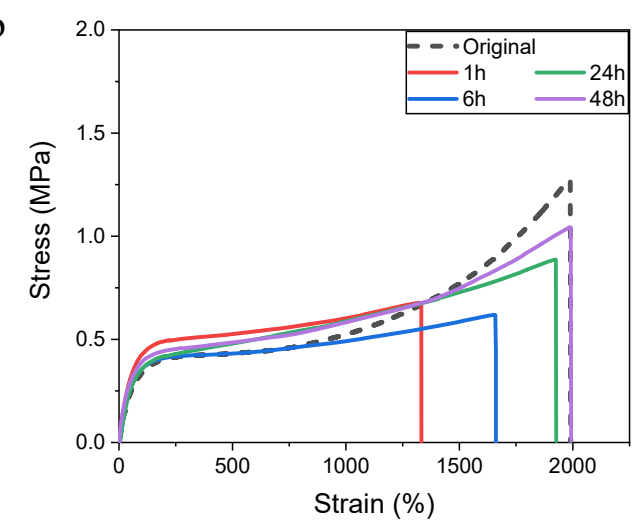

Figure 4. (a) Macro-graphs of cut and self-healed samples: two dumb-bell samples of PA36,36(24h) were respectively cut into two portions; one of each was brought together and remained in contact for 1 minute under ambient conditions for self-healing and subsequently stretching. Representative tensile stress-strain curves of PA36,36(24h) samples self-healed under ambient conditions for various lengths of time.

Conventional polyamide-based thermoplastic elastomers are not self-healing and need modification to have such characteristic. ${ }^{52}$ Without any modification or external stimulus, PA36,36(24h) displays autonomous self-healing under ambient conditions. A sample of PA36,36(24h) was cut into two portions which were subsequently re-contacted for $1 \mathrm{~min}$ before being left at room temperature $(\sim 16$ ${ }^{\circ} \mathrm{C}$ ) for different periods of time (Figure 4a,b). After only $1 \mathrm{~h}$ the self-healed polymer can be streched to $1614 \pm 246 \%$, and after $48 \mathrm{~h}$ it can be stretched to $1915 \pm 199 \%$ which is $99 \%$ of the average strain at break of the original sample before cutting. The tensile strength of the self-healed polymer also shows a reasonably high self-healing efficiency of $81 \%$ after $48 \mathrm{~h}$. Such a high self-healing 
performance is remarkable for a wholly biobased material. Compared to some other research on biobased self-healing polymers, PA36,36(24h) shows its superiority in terms of higher healing efficiency, shorter healing time and no requirement of external stimulus. For example, biobased Eucommia ulmoides ester elastomer only showed a healing efficiency of $25 \%$ in the strain after $24 \mathrm{~h}$ under ambient conditions $\left(20^{\circ} \mathrm{C}\right) .{ }^{53}$ Meanwhile the efficiency of tensile strength recovered was $58 \%$ after $24 \mathrm{~h}$. Exposidized soybean oil with citric acid polymer network required $2 \mathrm{~h}$ to recover $\sim 70 \%$ of its original strain and stress at a high temperature of $160{ }^{\circ} \mathrm{C} .{ }^{54}$ Polybutylene furanoate-bismaleimide blended with biobased polyurethane showed a healing efficiency of $81.6 \%$ in the strain and $81.1 \%$ in the tensile strength when heated at $50{ }^{\circ} \mathrm{C}$ after 3 days. ${ }^{55}$

As mentioned above and illustrated in Figure 1a,b, each of the monomers of PA36,36 has four dangling chains containing multiple methyl groups. After polymerization, the dangling chains and the main long alkyl chains in the polymer create abundant van der Waals bonds between methyl groups like a supramolecular network which are strong (given their large amount), dynamic and reversible. ${ }^{20,56}$ Upon physical damage, the van der Waals bonds break, and the tethered chains change back to free dangling chains leading to entropic increase. ${ }^{57}$ When the two broken polymer parts are brought back together, the dangling and the main chains diffuse from one part to the other and strong van der Waals bonds form again between chains until the entropy of the system comes back to the equilibrium state causing the polymer to self-heal. ${ }^{58}$

Another interesting property of PA36,36 is hydrophobicity which to the best of our knowledge is the first aliphatic polyamide to have such a feature. Figure 5a shows the comparison of PA36,36(24h) after being immersed in water for $24 \mathrm{~h}$, along with other polyamides reported elsewhere. ${ }^{33,59}$ PA36,36(24h) shows zero water uptake after 24 h's water immersion indicating superhydrophobicity. The low ratio of amide to methylene group in the polymer contributes to little hydrogen bonding and hence superhydrophobicity. Another reason for hydrophobicity in PA36,36 is the origin of the monomer. Pripol 1009 and Priamine 1075 are obtained from long-chain fatty diacid and fatty diamine which are hydrophobic. Fatty diacid and fatty diamine contain both polar chain ends and non-polar 
hydrocarbon chain, and the ratio between the two components controls water absorption. The hydrophobicity of PA36,36(24h) is confirmed by water contact angle $(\theta)$ measurement (Figure 5b). Hydrophobic materials are defined when their $\theta>90^{\circ}$. The $\theta$ of PA36,36(24) is $92.4^{\circ} \pm 1.93^{\circ}$. Compared to other PAs such as PA6 $\left(\theta=69.2^{\circ}\right)$ and PA12 $\left(\theta=77^{\circ}\right),{ }^{60}$ PA36,36(24h) possesses the highest water contact angle.

a

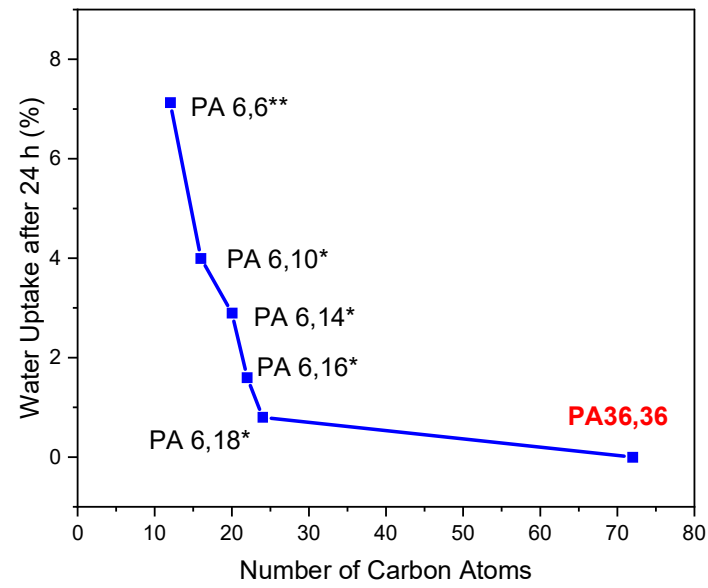

$\mathrm{b}$

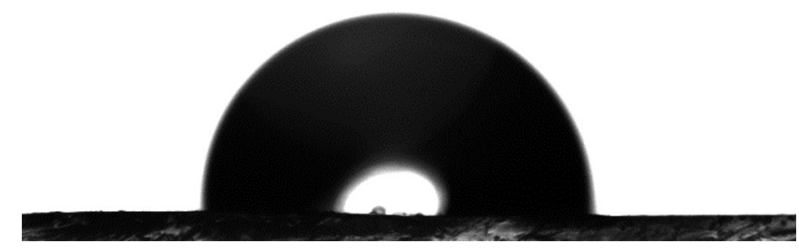

c

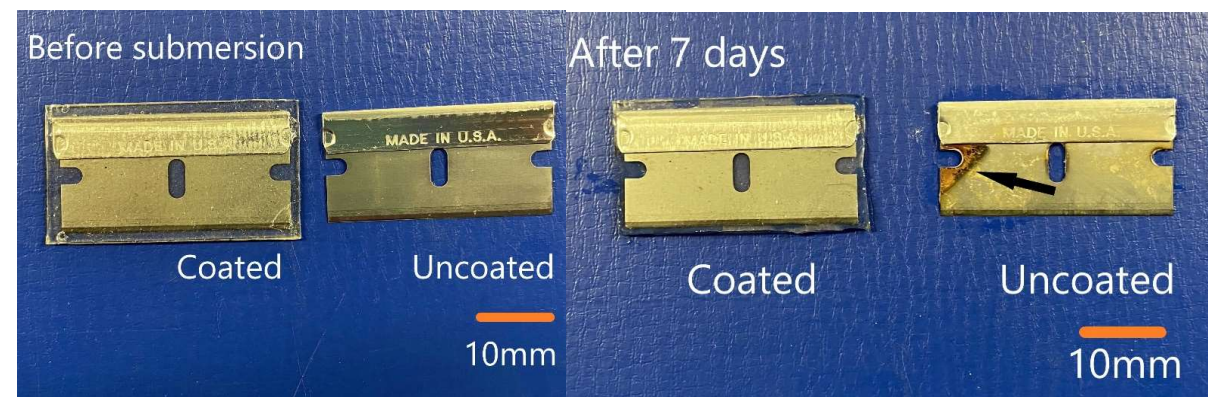

Figure 5. (a) Water uptake of PAs of different lengths of the monomers (data ${ }^{* 33}{ }^{* * 59}$ ). (b) Representative micro-graph of water contact angle measurement of PA36,36(24h). (c) Macro-graphs of stainless steel razor blades with and without PA36,36(24h) coating, before and after immersion in a $\mathrm{NaCl}$ water solution.

The high content of non-polar parts (hydrocarbon) of both monomers gives rise to materials with low water absorption. The ability to have zero water uptake offers high potential to PA36,36 in anticorrosion coatings for products in salty environments like the oceans. To test anti-corrosion 
performance, PA36,36(24h) was coated onto stainless steel razors by hot pressing a polymer sheet with a thickness of $0.5 \mathrm{~mm}$ onto each side of the razor. Both the coated and uncoated razors (controlled sample) were immersed in $4 \mathrm{wt} \%$ sodium chloride $(\mathrm{NaCl})$ water solution and left at ambient temperature $\left(\sim 16^{\circ} \mathrm{C}\right)$ for 7 days. The uncoated stainless steel depicts signs of rust while the coated steel remains unchanged (Figure 5c). The hydrophobicity of PA36,36(24h) prevented the metal surfaces from corrosion in the salty medium. Furthermore, the self-healing ability of PA36,36 is an additional attractive feature for anti-corrosion coatings as it will ensure long-term protection.
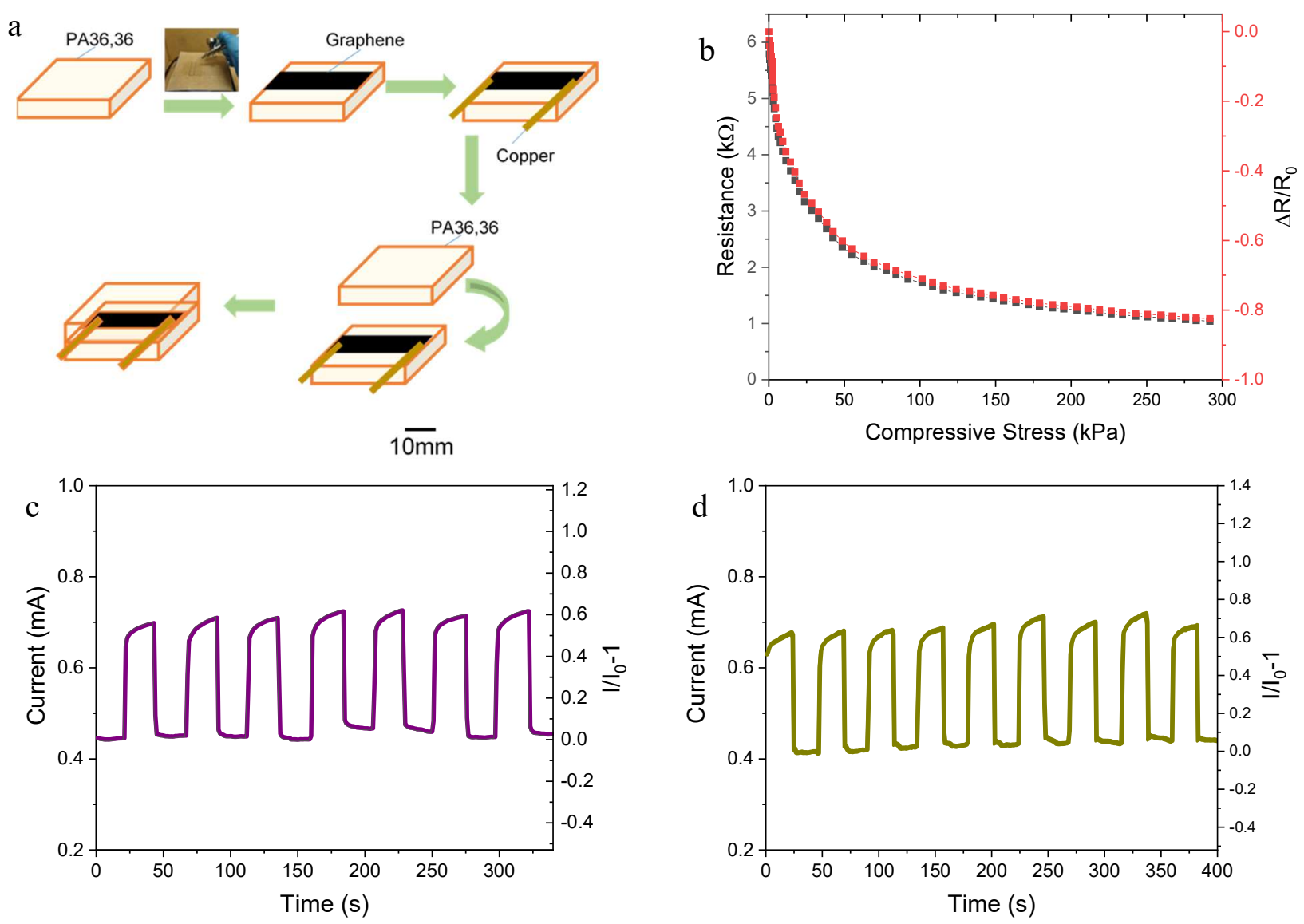

Figure 6. (a) Schematic illustration of sensor production procedure, including spray coating of graphene nanoplatelets onto a PA36,36(24h) substrate followed by pressing another sheet of the same polymer on top. (b) Piezoresistive response of the sensor to increasing pressure. (c) Piezoresistive response of the sensor under a dynamic pressure of $6 \mathrm{kPa}$, measured in current (I). (d) Piezoresistive response of the sensor under a dynamic pressure of $6 \mathrm{kPa}$ after damage and self-healing for $\sim 20 \mathrm{~s}$. 
PA36,36(24h) with the remarkable stretchability and flexibility was chosen as the substrate for the production of flexible electrodes for pressure sensing. A PA36,36(24h) sheet was spray coated with electrically conductive graphene nanoplatelets (GNPs) and laminated with another sheet of PA36,36(24h) to create a sandwich configuration sensor (Figure 6a). The resistance decreases in a non-linear relation with the pressure (Figure 6b). During compressive loading, the sliding and maybe reorientation of GNPs in the sensor increases the contact area between the GNPs and PA36,36(24h) which leads to lower resistance $(R)$. The relative resistance change $(\Delta R / R)$ decreases rapidly when the pressure is less than $50 \mathrm{kPa}$ and even slower when the pressure is higher because the saturation gradually occurs in the contact area. ${ }^{61}$

Generally, piezoresistive sensors display the sensitivity in three different ranges of pressure: $1 \mathrm{~Pa}-$ $1 \mathrm{kPa}$ suitable for detecting small living organism movements and subtle mechanical loading; $1-10$ $\mathrm{kPa}$ suitable for detecting normal touches and $10-100 \mathrm{kPa}$ for object manipulation. ${ }^{62}$ The sensitivity of the PA36,36(24h)/GNP/PA36,36(24h) sandwich sensor lies between 3 to $50 \mathrm{kPa}$ which is suitable for sensing applications, for example electronic skin, finger sensors, and large touch displays. The dynamic response of the sandwich sensor was measured under $6 \mathrm{kPa}$ pressure (Figure 6c). Under repeated compressive loading, the sensor has a relatively constant response, indicating good reproducibility and stability. To demonstrate its self-healing ability, the sensor was vertically cut from the top polymer layer through to the GNP coating layer and part of the bottom polymer layer using a sharp knife, and left for $\sim 20 \mathrm{~s}$ to self-heal. The self-healed sensor displays the same dynamic response to repeated pressure (Figure 6d) as for the original sensor, confirming excellent self- healing ability. 

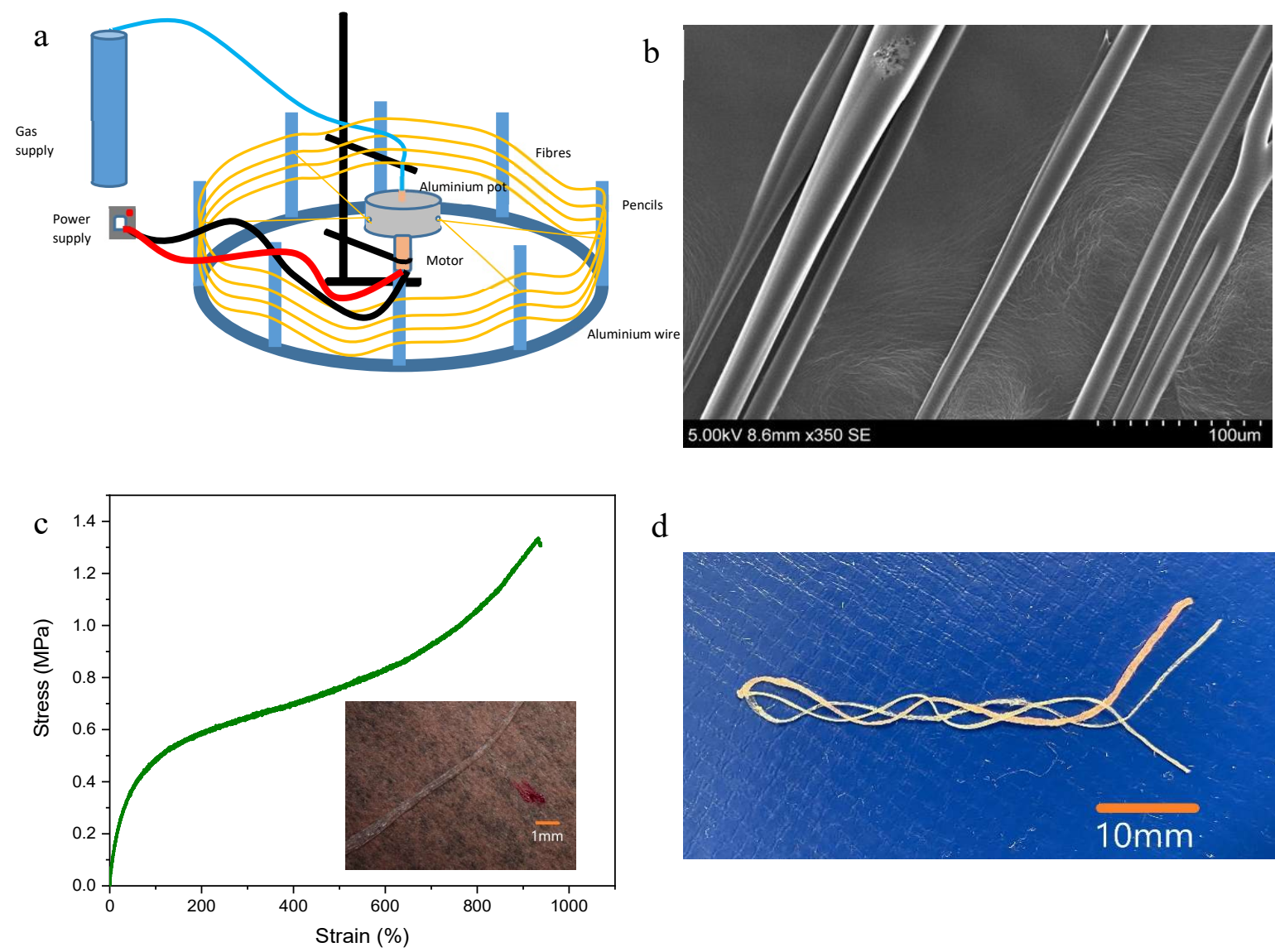

d

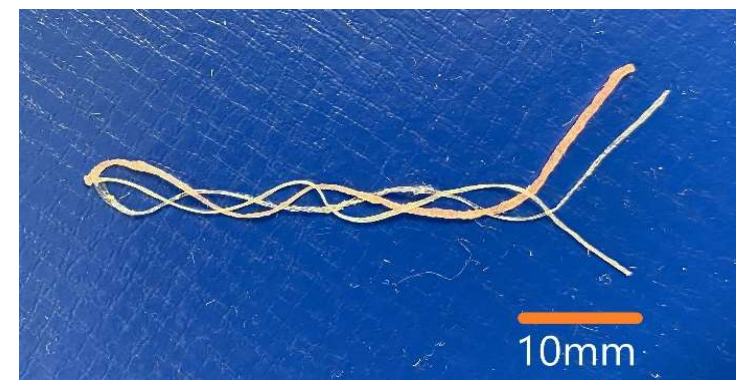

Figure 7. (a) The setup of pressurized gyration to prepare PA36,36(24h) microfibres. (b) Scanning electron micrograph (SEM) of PA36,36(24h) microfibres. (c) Representative tensile stress-strain curve of a fibre yarn (inset: optical micrograph of the yarn, with approximately 25 fibres). (d) Example of three loosely braided fibre yarns including an orange-dyed one.

To meet the increasing demand for stretchable apparel, the development of highly elastic fibres is required to achieve free body movements and minimise the risks of injury by reducing friction between the apparel and human skin. Besides, the increasing demand of synthetic fibres requires an alternative option to reduce the use of petrochemical resources by using more renewable feedstocks such as non-editable plant oils. Here, we use PA36,36(24h) to achieve the need for the required biobased textiles and highly elastic fibres through a pressurized gyration process (Figure 7a). As shown in Figure $\mathbf{7 b}$, single fibres with a diameter of $14.20 \pm 1.35 \mu \mathrm{m}$ were successfully and continously spun from PA36,36(24h), confirming its excellent spinnability. 
Tensile testing of a PA36,36(24h) yarn with around 25 single fibres (Figure 7c) confirms its outstanding stretchability with an elongation at break of $950 \pm 74 \%$. This elongation at break is higher than the polyurethane Spandex $(500-600 \%)$, polyester Spandex $(650-700 \%)$, polyether Spandex $(480-550 \%)$ and natural rubber fibre $(600-700 \%) .{ }^{63}$ The tensile strength of the yarn is $1.02 \pm 0.50$ MPa. Figure 7d displays three loosley braided yarns with one of them dyed in orange, showing its dyeability and the possibility of this novel self-healing highly elastic fibre to be further processed into desirable textile textures. The remarkable properties exhibited by these microfibres may also enable them to be explored in other applications such as fibre-based wearable electronics or soft robotics when incorporated with other functions. ${ }^{64}$

\section{Conclusions}

A highly stretchable, tough, superhydrophobic, wholly biobased polyamide-based thermoplastic elastomer with room temperature autonomous self-healing ability was successfully prepared. The polymerization time was varied to obtain the optimum reaction condition in a simple one-pot synthetic method without the involvement of any toxic chemical compounds. The PA36,36s show a high weight average molecular weight in the range of $142,400-185,600 \mathrm{~g} \cdot \mathrm{mol}^{-1}$ and a high thermal degradation temperature of $471-473{ }^{\circ} \mathrm{C}$. A rubbery plateau for the PA36,36s was detected between $10-50{ }^{\circ} \mathrm{C}$ with storage modulus of $1-4 \mathrm{MPa}$, implying elastomeric behaviour. The PA36,36s display a low $\mathrm{T}_{\mathrm{g}}$ of $3.1-4.1{ }^{\circ} \mathrm{C}$ that facilitates the autonomous room temperature self-healing ability. The elastomer possesses superior stretchability (up to 22.9 times its original length), high toughness (up to $14.21 \mathrm{MJ} . \mathrm{m}^{-3}$ ) and good shape recovery (total shape recovery from $500 \%$ within $30 \mathrm{~min}$ ). This is the first self-healing aliphatic polyamide elastomer reported, which is melt processable and hydrophobic. The elastomer shows autonomous self-healing with a healing efficiency of $99 \%$ in 48

h. The excellent self-healing behaviour is attributed to the high amount of van der Waals bonds from multiple dangling chains and the long entangled main alkyl chains, as well as intermolecular diffusion. The elastomer is also hydrophobic, confirmed by its zero water uptake after 24 h's water 
immersion and high water contact angle $\left(92.4^{\circ}\right)$, which is a distinctive feature compared to conventional water-absorbing polyamides.

The remarkable properties of the self-healing thermoplastic elastomer allows for the fabrication of anti-corrosion coatings, piezoresistive sensors, and highly stretchable microfibres. The optimal PA36,36 shows excellent anti-corrosion perfomance with no rust formed after 7 days in a salt solution when coated on the surface of a stainless steel razor. A piezoresistive sensor prepared by sandwiching conductive graphene nanoplatelets between two PA36,36(24h) substrates shows non-linear piezoresistive effects, good repeatability and excellent self-healing ability. PA36,36(24h) microfibres were successfully fabricated by pressurized gyration of and their yarn possesses superior stretchability (950\%) compared to existing commercial elastane fibres. These demonstrate high potential of the new renewable self-healing elastomer in broad applications.

\section{Materials and Methods}

\section{Materials}

The fatty dicarboxylic acid under the tradename Pripol 1009 and fatty diamine Priamine 1075 were kindly provided by CRODA International Plc. Pripol 1009 was hydrogenated and low viscous liquid which was produced by coupling reactions of unsaturated fatty acid and contained more than $98.5 \%$ dimer acid. Priamine 1075 was yellow, slightly higher viscous liquid with dimer content $99 \%$. Graphite nanoplatelets (surface area: $500 \mathrm{~m}^{2} \cdot \mathrm{g}^{-1}$ ) were purchased from Alfa-Aesar. Sodium chloride ( $\geq 99 \%$ ), isopropanol ( $\geq 99 \%)$, chloroform ( $\geq 99 \%)$, tetrahydrofuran (HPLC grade, 99.9\%), triethylamine ( $\geq 99 \%$ ), butylated hydroxytoluene inhibitor ( $>99 \%$ ) and dimethyl sulfoxide ( $\geq 99.5 \%)$ were purchased from Sigma-Aldrich.

Synthesis of polyamide 36,36s

PA36,36 was synthesized by melt polycondensation of Pripol 1009 and Priamine 1075 under a nitrogen environment. Equimolar amounts of Pripol 1009 and Priamine 1075 were placed in a threeneck flask which was equipped with a mechanical stirrer, a condenser and nitrogen inlet. To prevent 
excessive foaming, the reaction temperature was gradually increased by $20^{\circ} \mathrm{C}$ every 20 minutes until reaching $220^{\circ} \mathrm{C}$. Four polymers with different polymerization times were synthesized at $220{ }^{\circ} \mathrm{C}: 8$ $\mathrm{h}, 16 \mathrm{~h}, 24 \mathrm{~h}$ and $32 \mathrm{~h}$.

\section{Characterization of polyamide $36,36 \mathrm{~s}$}

Fourier Transform infrared spectra were recorded on a Perkin-Elmer Spectrum 100 with attenuated total reflectance mode in the wavenumber region of 4000 to $650 \mathrm{~cm}^{-1}$, with a resolution of $1 \mathrm{~cm}^{-1}$. Molecular weights were determined by Gel Permeation Chromatography using an Agilent Technologies 1260 Infinity GPC system with Cirrus GPC software, a guard column and two PL gel $5 \mu \mathrm{m}$ MIXED-C columns (PS/DVB) connected in a series operating at $25{ }^{\circ} \mathrm{C}$. The eluent used was tetrahydrofuran containing $2.0 \% \mathrm{v} / \mathrm{v}$ triethylamine and $0.05 \% \mathrm{w} / \mathrm{v}$ butylated hydroxytoluene inhibitor, with a flow rate of $1.0 \mathrm{~mL} \cdot \mathrm{min}^{-1}$. A refractive index detector was used operating at $30{ }^{\circ} \mathrm{C}$. Dimethyl sulfoxide was used as a flow rate marker. For the calibration, a series of ten nearmonodisperse poly(methyl methacrylate) standards from Agilent were used, with molecular weights of $1,010,1,950,6,850,13,900,31,110,68,750,137,800,320,000,569,000$ and 1,048,000 g.mol ${ }^{-1}$.

Thermal Gravimetric Analysis was conducted on a Q50 TGA instrument (TA Instruments) in the presence of nitrogen flow at a rate of $50 \mathrm{~mL} \cdot \mathrm{min}^{-1}$. The weight loss of the samples $(16-32.0 \mathrm{mg})$ was recorded by heating the samples up to $600{ }^{\circ} \mathrm{C}$ at a heating rate of $10{ }^{\circ} \mathrm{C} \cdot \mathrm{min}^{-1}$. Dynamic mechanical analysis was performed on a Tritec 2000 model in compressed mode. The samples with diameter $6 \mathrm{~mm}$ and thickness $4 \mathrm{~mm}$ were tested from $-80{ }^{\circ} \mathrm{C}$ to $100{ }^{\circ} \mathrm{C}$ with a heating rate $2{ }^{\circ} \mathrm{C} / \mathrm{min}$ at a $1 \mathrm{~Hz}$ frequency.

The tensile stress-strain curves were obtained with a Lloyds LRX universal testing machine equipped with a $50 \mathrm{~N}$ load cell. The tests were performed at room temperature with a cross-head speed of 100 $\mathrm{mm} \cdot \mathrm{min}^{-1}$. A Rondol heated hydraulic platen press was used to prepare test specimens. Samples in a mould with dimensions $10 \mathrm{~cm}$ x $10 \mathrm{~cm} \times 1 \mathrm{~mm}$ were placed between the hydraulic press and heated to $120{ }^{\circ} \mathrm{C}$ and pressed for $4 \mathrm{~min}$. Subsequently, the hot-pressed films were cut into dumb-bell shape 
according to British Standard ISO-37 type 3, by using a punching machine. At least five specimens were tested for each material. Loading-unloading tests were performed at a strain rate of $100 \mathrm{~mm} . \mathrm{min}^{-}$ ${ }^{1}$ using the same universal testing machine. Some specimens were stretched to $500 \%$, unloaded at the same strain rate and rested for $30 \mathrm{~min}$ before being stretched again. Other specimens were stretched to $200 \%$ and rested for $15 \mathrm{~min}$.

Water uptake of PA36,36s was obtained by measuring their weights before and after immersion in water for $24 \mathrm{~h}$ at room temperature. After water immersion, samples were gently dried with a tissue to remove water on the surface. The water uptake was calculated with equation (1). Three samples were tested for each material.

$$
\text { Water uptake }=\frac{\text { Wwet-Wdry }}{\text { Wdry }} \times 100 \%
$$

Contact angle measurement was conducted with sessile drop using a Biolin Surface Tensiometer. A rectangular piece of PA36,36(24h) was placed on the top of a glass slide. Then, a drop of water with volume of $10 \mu \mathrm{L}$ was deposited at the top of PA 36,36 (24h) surface with a $50 \mu \mathrm{L}$ glass syringe. Ten different measurements were conducted on different spots of the specimen. The contact angle was obtained from the average of left and right angles of water drops. ${ }^{65}$

Self-healing efficiency was measured by cutting the polymer samples into two halves using a razor blade, which were immediately put back into contact for $1 \mathrm{~min}$ by hand and left under ambient conditions for different periods of time. Self-healing efficiency was calculated by the ratio of the elongation at break or tensile strength between the healed sample and the original sample. Three samples were tested for each material.

\section{Preparation and assessment of anti-corrosion coatings}

PA36,36(24h) was prepared into sheets with dimensions $100 \mathrm{~mm} \times 100 \mathrm{~mm}$ x $0.5 \mathrm{~mm}$, by hot pressing at $120{ }^{\circ} \mathrm{C}$ for $4 \mathrm{~min}$. A sheet was laminated onto a stainless razor blade $(38.1 \mathrm{~mm} \times 19.0 \mathrm{~mm})$ by 
pressing at $120^{\circ} \mathrm{C}$. The excess material was scraped off. Both the polymer-coated and the uncoated blades were immersed in a water solution of $4 \mathrm{wt} \% \mathrm{NaCl}$ and left at ambient temperature for 7 days.

\section{Fabrication and evaluation of piezoresistive sensors}

Graphene nanoplatelets were dispersed in isopropanol in a glass beaker at a concentration of 2 mg.mL $L^{-1}$ and sonicated for $1 \mathrm{~h}$ using a sonication bath (Fisherbrand). A PA36,36(24h) layer film with dimensions $30 \mathrm{~mm}$ x $30 \mathrm{~mm}$ x $1 \mathrm{~mm}$ was used as the base layer of the sensor, then the GNP dispersion was sprayed onto the middle of the film with a width of $20 \mathrm{~mm}$. In the spraying process, the film was placed on Teflon film while being heated on a hot plate at $65^{\circ} \mathrm{C}$ to evaporate isopropanol quickly. After that another PA36,36(24h) layer was placed above the coated GNP layer. The sandwich was heated at $65{ }^{\circ} \mathrm{C}$ for $10 \mathrm{~min}$ to stick the two layers together and prevent the GNPs from leaking. ${ }^{66}$ The piezoresistivity measurement was conducted by applying various external pressure using the Lloyd LS5 universal testing machine to the sample while measure the resistance and current using a Agilent benchtop digital multimeter 34450A with two probe method.

\section{Manufacture and characterization of highly stretchable fibres}

PA36,36(24h) fibres were manufactured by pressurised gyration. Briefly, a cylindrical aluminium vessel, with two orifices on the wall, was connected to a DC motor, which can form oriented microand nanofibers by ejecting polymer solution as the vessel rotates at a high speed. PA36,36 solution was prepared by dissolving in chloroform at a concentration of $10 \mathrm{wt} \%$. During gyration, the working pressure was set to $1 \times 10^{5} \mathrm{~Pa}$ by using the pressure of inlet $\mathrm{N}_{2}$ gas into the vessel, and the rotational speed at $3.6 \times 10^{4} \mathrm{rpm}$ using a bi-directional regulator run for $2 \mathrm{~s}$. As-spun fibres were collected randomly as an overlaid mat on aluminium foil placed on the inner wall of the collector.

SEM was carried out on a JSM-6301F scannning electron microscope. The micrographs were recorded at an operating voltage of $20 \mathrm{kV}$ and an emission current of $6 \mu \mathrm{A}$ to obtain high-resolution images. The tensile testing of fibre yarns was conducted using a Zwick universal testing machine with a $20 \mathrm{~N}$ load cell at a crosshead speed of $20 \mathrm{~mm} \cdot \mathrm{min}^{-1}$. The diameter of the yarns was measured 
from micrographs obtained using a Nikon Eclipse SMZ800 optical microscope. Ten samples were tested.

\section{Acknowledgments}

YN thanks the Indonesia Endowment Fund for Education (LPDP) for a PhD scholarship. AA thanks the Malaysian Government and University College London for a $\mathrm{PhD}$ and a postdoctoral scholarship. Gavin Irvine is thanked for helping with part of the GPC measurements.

\section{Supporting Information}

The supporting information associated with this article can be found in the online version.

NMR graphs of the monomers and PA36,36s, and their discussion; GPC graph of PA36,36s after hot pressing; DTG graph of PA36,36s; table of molecular weight data of PA36,36s; table of thermal degradation and glass transition temperatures of PA36,36s.

\section{Author Information:}

Corresponding Authors

*E-mail: b.chen@qub.ac.uk

ORCID

Yeyen Nurhamiyah: 0000-0002-2353-2144

Biqiong Chen: 0000-0002-6465-2871

Efrosyni Themistou: 0000-0002-2335-3584

Notes

The authors declare no competing financial interest.

\section{References}

(1) McDonel, E. T.; Baranwal, K. C.; Andries, J. C. Polymer Blends, Academic Press, 1978. 
(2) Yoda, R. Elastomers for biomedical applications. J. Biomater. Sci. Polym. Ed. 1998, 9, 561626.

(3) Gerratt, A. P.; Michaud, H. O.; Lacour, S. P. Elastomeric Electronic Skin for Prosthetic Tactile Sensation. Adv. Funct. Mater. 2015, 25, 2287-2295.

(4) Xu, J.; Wang, S.; Wang, G.-J. N.; Zhu, C.; Luo, S.; Jin, L.; Gu, X.; Chen, S.; Fei, V. R.; To, J. W. F.; Rondeau-Gagné, S.; Park, J.; Schroeder, B. C.; Lu, C.; Oh, J. Y.; Wang, Y.; Kim, Y.-H.; Yan, H.; Sinclair, R.; . Zhou, D; Xue, G.; Murmann, B.; Linder, C.; Cai, W.; Tok, J. B.-H.; Chung, J. W.; Bao, Z. Highly stretchable polymer semiconductor films through the nanoconfinement effect. Science 2017, 355, 59-64.

(5) Kim, Y.; Yuk, H.; Zhao,R.; Chester, S. A.; Zhao, X. Printing ferromagnetic domains for untethered fast-transforming soft materials. Nature 2018, 558, 274-279.

(6) Huang, S.; Liu, Y.; Zhao, Y.; Ren, Z.; Guo, C. F. Flexible Electronics: Stretchable Electrodes and Their Future. Adv. Funct. Mater. 2019, 29, 1805924.

(7) Wu, T.; Chen, B. Synthesis of Multiwalled Carbon Nanotube-Reinforced Polyborosiloxane Nanocomposites with Mechanically Adaptive and Self-Healing Capabilities for Flexible Conductors. ACS Appl. Mater. Interfaces 2016, 8, 24071-24078.

(8) Nasresfahania, A.; Zelisko, P. M. Synthesis of a self-healing siloxane-based elastomer crosslinked via a furan-modified polyhedral oligomeric silsesquioxane: investigation of a thermally reversible silicon-based cross-link. Polym. Chem. 2017, 8, 2942-2952.

(9) Wang, J. K.; Lv, C.; Li, Z. X.; Zheng, J. P. Facile Preparation of Polydimethylsiloxane Elastomer with Self-Healing Property and Remoldability Based on Diels-Alder Chemistry. Macromol. Mater. Eng. 2018, 303, 1800089. 
(10) Li, X.; Yu, R.; He, Y.; Zhang, Y.; Yang, X.; Zhao, X.; Huang, W. Self-Healing Polyurethane Elastomers Based on a Disulfide Bond by Digital Light Processing 3D Printing. ACS Macro Lett. 2019, 8, 1511-1516.

(11) Yu, K. H.; Xin, A.; Du, H. X.; Li, Y.; Wang, Q. M. Additive manufacturing of self-healing elastomers. NPG Asia Mater. 2019, 11, 7.

(12) Cash, J. J.; Kubo, T.; Bapat, A. P.; and Sumerlin, B. S.; Room-Temperature Self-Healing Polymers Based on Dynamic-Covalent Boronic Esters. Macromolecules 2015, 48, 2098-2106.

(13) Wu, T.; Gray, E.; Chen, B. A self-healing, adaptive and conductive polymer composite ink for 3D printing of gas sensors. J. Mater. Chem. C 2018, 6, 6200-6207.

(14) Yoshida, S.; Ejima, H.; and N. Yoshie,; Tough Elastomers with Superior Self-Recoverability Induced by Bioinspired Multiphase Design. Adv. Funct. Mater. 2017, 27, 1701670.

(15) Kang, J.; Son, D.; Wang, G.-J. N.; Liu, Y.; Lopez, J.; Kim, Y.; Oh, J. Y.; Katsumata,T.; Mun, J.; Lee, Y.; Jin, L.; Tok, J. B. H.; Bao, Z.; Tough and Water-Insensitive Self-Healing Elastomer for Robust Electronic Skin. Adv. Mater. 2018, 30, 1706846.

(16) Mozhdehi, D.; Ayala, S.; Cromwell, O. R,; Guan, Z. Self-Healing Multiphase Polymers via Dynamic Metal-Ligand Interactions. J. Am. Chem. Soc. 2014, 136, 16128-16131.

(17) Li, C.-H.; Wang, C.; Keplinger, C.; Zuo, J.-L.; Jin, L.; Sun, Y.; Zheng, P.; Cao, Y.; Lissel, F.; C. Linder,; You, X.-Z.; Bao, Z.; A highly stretchable autonomous self-healing elastomer. Nat. Chem. 2016, 8, 618-624.

(18) Das, A.; Sallat, A.; Böhme, F.; Suckow, M.; Basu, D.; Wießner, S.; Stöckelhuber, K.W.; Voit, B.; Heinrich, G. Ionic Modification Turns Commercial Rubber into a Self-Healing Material. ACS Appl. Mater. Interfaces 2015, 7, 20623-20630. 
(19) Liu, J.; Tan, C. S. Y.; Yu, Z.; Li, N.; Abell, C.; Scherman, O. A. Tough Supramolecular Polymer Networks with Extreme Stretchability and Fast Room-Temperature Self-Healing. Adv. Mater. $2017,29,1605325$.

(20) Urban, M. W.; Davydovich, D.; Yang, Y.; Demir, T.; Zhang, Y.; Casabianca, L. Key-and-lock commodity self-healing copolymers. Science 2018, 362, 220-225.

(21) J. Wu,; L.-H. Cai,; Weitz, D. A. Tough Self-Healing Elastomers by Molecular Enforced Integration of Covalent and Reversible Networks. Adv. Mater. 2017, 29, 1702616.

(22) Cordier, P.; Tournilhac, F.; Soulié-Ziakovic, C.; Leibler, L.; Self-healing and thermoreversible rubber from supramolecular assembly. Nature 2008, 451, 977-980.

(23) Kim, S. M.; Jeon, H.; Shin, S. H.; Park, S. A.; Jegal, J.; Hwang, S. Y.; Oh, D. X.; Park, J.; Superior Toughness and Fast Self-Healing at Room Temperature Engineered by Transparent Elastomers. Adv. Mater. 2018, 30, 1705145.

(24) Rao, Y.-L.; Chortos, A.; Pfattner, R. ; Lissel, F.; Chiu, Y.-C. ; Feig, V.; Xu, J.; Kurosawa, T.; Gu, X.; Wang, C.; He, M.; Chung, J. W.; Bao, Z.; Stretchable Self-Healing Polymeric Dielectrics Cross-Linked Through Metal-Ligand Coordination J. Am. Chem. Soc. 2016, 138, 6020-6027.

(25) Guo, W.; Wang, X.; Lu, Xi.; Li, X.; Li, Y.; Sun, J. Plant oil and amino acid-derived elastomers with rapid room temperature self-healing ability. J. Mater. Chem. A. 2019, 7, 21927-21933.

(26) Pagacz, J.; Raftopoulos, K. N.; Leszczyńska, A.; Pielichowski, K. Bio-polyamides based on renewable raw materials. $J$. Therm. Anal. Calorim. 2016, 123, 1225-1237.

(27) Tao, L.; Liu, K.; Li, T.; Xiao, R. Preparation and properties of biobased polyamides based on 1,9-azelaic acid and different chain length diamines. Polym. Bull. 2020, 77, 1135-1156. 
(28) Lee, Y. H.; B. Kang, K.; Kim, H. D.; Yoo, H. J.; Kim, J. S.; Huh, J. H.; Jung, Y. J.; Lee,D. J. Effect of hot pressing/melt mixing on the properties of thermoplastic polyurethane. Macromol. Res. 2009, 17, 616-622.

(29) Martino, L.; Basilissi, L.; Farina, H.; Ortenzi, M. A.; Zini, E.; Silvestro, G. D.; Scandola, M.; Bio-based polyamide 11: Synthesis, rheology and solid-state properties of star structures. Eur. Polym. J. 2014, 59, 69-77.

(30) Levchik, S. V.; Weil, E. D.; Lewin, M.; Thermal decomposition of aliphatic nylons. Polym. Int. $1999,48,532-557$.

(31) Herrera, M.; Matuschek, G.; Kettrup, A.; Main products and kinetics of the thermal degradation of polyamides. Chemosphere 2001, 42, 601-607.

(32) Voorhaar, L.; Diaz, M. M.; Leroux, F.; Rogers, S.; Abakumov, A. M.; G. V. Tendeloo,; Assche, G. V.; Mele, B. V.; Hoogenboom, R. Supramolecular thermoplastics and thermoplastic elastomer materials with self-healing ability based on oligomeric charged triblock copolymers. NPG Asia Mater. 2017, 9, e385.

(33) Nguyen, P. H.; Spoljaric, S.; Seppälä, J. Redefining polyamide property profiles via renewable long-chain aliphatic segments: Towards impact resistance and low water absorption. Eur. Polym. J. 2018, 109, 16, 16-25.

(34) Yang Y.; Ding, X.; Urban, M.W. Chemical and physical aspects of self-healing materials, Prog. Polym. Sci. 2015, 49-50, 34-59.

(35) Lips, P. A. M; Broos, R.; van Heeringen, M. J. M; Dijkstra, P.J.; Feijen, J. Synthesis and characterization of poly(ester amide)s containing crystallizable amide segments. Polymer 2005, $46,7823-7833$ 
(36) Biemond, G. J. E.; Feijen, J.; Gaymans, R. J. Segmented Block Copolymers with Monodisperse Hard Segments: The Influence of H-Bonding on Various Properties. Macromol. Mater. Eng. 2009, 294, 492-501.

(37) Haque, M. A.; Kurokawa,T.; Gong, J. P. Super tough double network hydrogels and their application as biomaterials. Polymer 2012, 53, 1805-1822.

(38) Quiles-Carrillo, L.; Montanes, N.; Boronat, T.; Balart, R.; Torres-Giner, S. Evaluation of the engineering performance of different bio-based aliphatic homopolyamide tubes prepared by profile extrusion. Polym. Test. 2017, 61, 421-429.

(39) Liu, K.; Madbouly, S. A.; Schrader, J. A.; Kessler, M. R.; Grewell, D.; Graves, W. R. Biorenewable polymer composites from tall oil-based polyamide and lignin-cellulose fiber. $J$. Appl. Polym. Sci. 2015, 132, 42592.

(40) Hablot, E.; Donnio, B.; Bouquey, M.; Avérous, L. Dimer acid-based thermoplastic biopolyamides: Reaction kinetics, properties and structure. Polymer 2010, 51, 5895-5902.

(41) Song, L.; Zhu, T.; Yuan, L.; Zhou, J.; Y. Zhang,; Z. Wang,; Tang, C. Ultra-strong long-chain polyamide elastomers with programmable supramolecular interactions and oriented crystalline microstructures. Nat. Commun. 2019, 10, 1315.

(42) Sheth, J. P.; Xu, J.; Wilkes, G. L Solid state structure-property behavior of semicrystalline poly(ether-block-amide) PEBAX® thermoplastic elastomers. Polymer 2003, 44, 743-756.

(43) Chen, Y.; Kushner, A. M.; Williams, G. A.; Guan, Z. Multiphase design of autonomic selfhealing thermoplastic elastomers. Nat. Chem. 2012, 4, 467-472.

(44) Zhang, L. Z.; Liu, Z. H.; Wu, X. L.; Guan, Q. B.; Chen, S.; Sun, L. J.; Y. F.; Guo, S. L. Wang; Song, J. C.; Jeffries, E. M.; He, C. L.; Qing, F. L.; Bao, X. G.; and You, Z. W. A Highly Efficient Self-Healing Elastomer with Unprecedented Mechanical Properties. Adv. Mater. 2019, 31, 1901402. 
(45) Lv, C.; Zhao, K.; Zheng, J. A Highly Stretchable Self-Healing Poly(dimethylsiloxane) Elastomer with Reprocessability and Degradability. Macromol. Rapid Commun. 2018, 39, 1700686.

(46) Zhang, B., Zhang; P., Zhang; H., Yan; C., Zheng; Z., Wu; B., Yu, Y.,; A Transparent, Highly Stretchable, Autonomous Self-Healing Poly(dimethyl siloxane) Elastomer. Macromol. Rapid Commun. 2017, 38, 1700110.

(47) Flory, P. J. Tensile Strength in Relation to Molecular Weight of High Polymers. J. Am. Chem. Soc. 1945, 67, 2048-2050.

(48) Chen, L.; Sun, T. L.; Cui, K.; King, D. R.; Kurokawa, T.; Saruwatari, Y.; Gong, J. P. Facile synthesis of novel elastomers with tunable dynamics for toughness, self-healing and adhesion. J. Mater. Chem. A. 2019, 7, 17334-17344.

(49) Liu, J.; Liu, J.; Wang, S.; Huang, J.; Wu, S.; Tang, Z.; Guo,B.; Zhang, L. An advanced elastomer with an unprecedented combination of excellent mechanical properties and high self-healing capability. J. Mater. Chem. A 2017, 5, 25660-25671.

(50) Farida, K.; Thangavel, G.; Cai, G.; Zhou, X.; Park S.; Xiong J.; Lee, P. S.; Extremely stretchable and self-healing conductor based on thermoplastic elastomer for all-threedimensional printed triboelectric nanogenerator. Nat. Commun. 2019, 10, 2158.

(51) Bartolomé, L.; Aurrekoetxea, J.; Urchegui, M. A.; Tato, W. The influences of deformation state and experimental conditions on inelastic behaviour of an extruded thermoplastic polyurethane elastomer. Mater. Des. 2013 49, 974-980.

(52) Liu, Y.-L.; Chen, Y.-W. Thermally Reversible Cross-Linked Polyamides with High Toughness and Self-Repairing Ability from Maleimide- and Furan-Functionalized Aromatic Polyamides. Macromol. Chem. Phys. 2007, 208, 224-232. 
(53) Qi, X.; Zhang, J.; Zhang, L.; Yueb, D. Bio-based self-healing Eucommia ulmoides ester elastomer with damping and oil resistance. J. Mater. Sci. 2020, 55, 4940-4951.

(54) Altuna, F. I.; Pettarin,V.; Williams, R. J. J. Self-healable polymer networks based on the crosslinking of epoxidised soybean oil by an aqueous citric acid solution. Green Chem. 2013, 15, $3360-3366$.

(55) Ryu, Y.S.; Oh, K.W.; Kim, S.H. Synthesis and characterization of a furan-based self-healing polymer. Macromol. Res. 2016, 24, 874-880 .

(56) Susa, A.; Bose, R. K.; Grande, A. M.; van der Zwaag, S.; Garcia, S. J. Effect of the Dianhydride/Branched Diamine Ratio on the Architecture and Room Temperature Healing Behavior of Polyetherimides. ACS Appl. Mater. Interfaces 2016, 8, 34068-34079.

(57) Yang, Y.; Urban, M.W. Self-healing polymeric materials, Chem. Soc. Rev. 2013, 42 74467467.

(58) Wool, R. P.; O’Connor, K. M. A theory crack healing in polymers. J. Appl. Phys. 1981, 52, 5953-5963.

(59) Boussia, A. C.; Vouyiouka, S. N.; Porfiris, A. D.; Papaspyrides,C. D. Long-Aliphatic-Segment Polyamides: Salt Preparation and Subsequent Anhydrous Polymerization. Macromol. Mater. Eng. 2010, 295, 812-821.

(60) Extrand, C. W. Water Contact Angles and Hysteresis of Polyamide Surfaces. J. Colloid Interface Sci. 2002, 248, 136-142.

(61) Lv, B.; Chen, X.; Liu, C.; A Highly Sensitive Piezoresistive Pressure Sensor Based on Graphene Oxide/Polypyrrole@Polyurethane Sponge. Sensors 2020,20, 1219-1233.

(62) Benight, S. J.; Wang, C.; Tok, J. B. H.; and Bao, Z. Stretchable and self-healing polymers and devices for electronic skin. Prog. Polym. Sci., 2013, 38, 1961-1977. 
(63) J. Hu, J. Lu, and Y. Zhu, New Developments in Elastic Fibers. Polym. Rev. 2008, 48, 275-301.

(64) Zeng, W.; Shu, L.; Li, Q.; Chen, S.; Wang, F.; Tao, X. M.; Fiber-Based Wearable Electronics: A Review of Materials, Fabrication, Devices, and Applications. Adv. Mater. 2014, 26, 53105336.

(65) Extrand, C. W. Water Contact Angles and Hysteresis of Polyamide Surfaces. J. Colloid Interface Sci. 2002, 248, 136-142.

(66) Zhao, H.; Yang, M. H.; . He, D. L; Liu, Y.; Bai, J. T.; Bai, J. B.; Effects of the shape features of graphite nanoplatelets on electrically-conductive behaviors of polydimethylsiloxane-based stretchable electrodes. Mater. Res. Express 2019, 6, 0850g1. 